NASA Technical Memorandum 106552

AIAA-94-3079

Army Research Laboratory Memorandum-ARL-TR-390

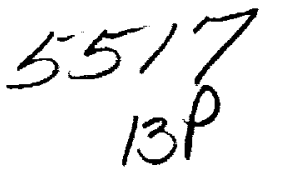

\title{
Spur, Helical, and Spiral Bevel Transmission Life Modeling
}

Michael Savage and Kelly L. Rubadeux

University of Akron

Akron, Ohio

and

Harold H. Coe and John J. Coy

Lewis Research Center

Cleveland, Ohio

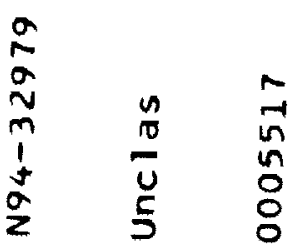

Prepared for the

30th Joint Propulsion Conference

cosponsored by the AIAA, SAE, ASME, and ASEE

Indianapolis, Indiana, June 27-29, 1994

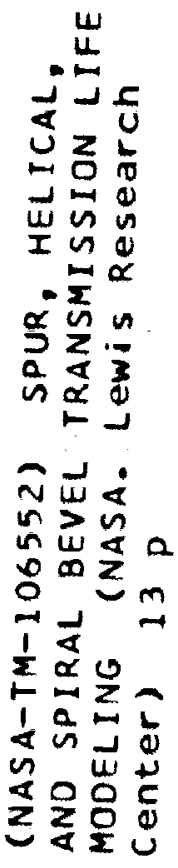

U.S. ARMY

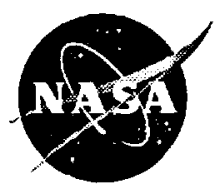

National Aeronautics and

Space Administration

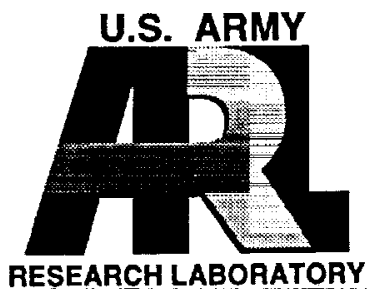




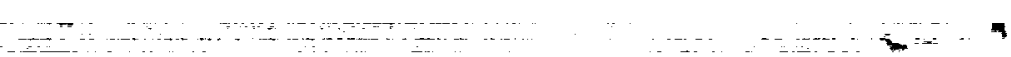




\title{
SPUR, HELICAL, AND SPIRAL BEVEL TRANSMISSION LIFE MODELING
}

\author{
Michael Savage and Kelly L. Rubadeux \\ The University of Akron \\ Department of Mechanical Engineering
}

Akron, Ohio 44325

and

Harold H. Coe and John J. Coy

National Aeronautics and Space Administration

Lewis Research Center

Cleveland, Ohio 44135

$\underline{\text { Abstract }}$

A computer program, TLIFE, which estimates the life, dynamic capacity, and reliability of aircraft transmissions, is presented. The program enables comparisons of transmission service life at the design stage for optimization. A variety of transmissions may be analyzed including: spur, helical, and spiral bevel reductions as well as series combinations of these reductions. The basic spur and helical reductions include: single mesh, compound, and parallel path plus reverted star and planetary gear trains. A variety of straddle and overhung bearing configurations on the gear shafts are possible as is the use of a ring gear for the output. The spiral bevel reductions include single and dual input drives with arbitrary shaft angles. The program is written in FORTRAN 77 and has been executed both in the personal computer DOS environment and on UNIX workstations. The analysis may be performed in either the SI metric or the English inch system of units. The reliability and life analysis is based on the two-parameter Weibull distribution lives of the component gears and bearings. The program output file describes the overall transmission and each constituent transmission, its components, and their locations, capacities, and loads. Primary output is the dynamic capacity and 90-percent reliability and mean lives of the unit transmissions and the overall system which can be used to estimate service overhaul frequency requirements. Two examples are presented to illustrate the information available for single element and series transmissions.

\section{Nomenclature}

a life adjustment factor

C dynamic capacity, $\mathrm{N}$

$F$ load, N

life (million cycles or hours)

Ln natural $\log$ function

$\boldsymbol{R}$ reliability $v$ load adjustment factor

$\Gamma$ gamma function

$\sum$ summing function

\section{Subscripts}

$a$ adjusted

$a v$ average

$i$ a counter

n total number

$r$ radial

$s$ system

1090 -percent reliability

\section{Exponents}

b Weibull slope

p load-life factor

\section{Introduction}

New transmissions which are lighter, smaller, and longer lasting than present transmissions would improve aircraft performance. ${ }^{1}$ The life of an aircraft transmission in this context is really the service time between overhauls, ${ }^{2}$ which is related to a transmission's eventual fatigue life in an unserviced state. Since testing for the eventual fatigue lives of prototype transmissions is very time consuming and expensive, optimization by experimentation is not reasonable.

However, computer optimization at the design stage offers the promise of improved transmission capability with affordable development costs. ${ }^{3,4}$ Computer programs are available for the life analysis of different bearings and bearing shaft configurations using the Lundberg-Palmgren fatigue life model. This theory has also been applied to the analysis of fatigue lives of spur and helical gears based on surface pitting as the eventual mode of failure. ${ }^{5,6}$ The statis- 
tical basis of the reliability analysis is the two-parameter Weibull distribution.

There are also analysis programs for life and dynamic capacity at a given reliability for planetary and bevel gear transmissions $^{7.9}$ and for a number of parallel shaft reductions. ${ }^{10}$

These simulations are limited in the number of configurations they can analyze. However, the parallel shaft reduction program (PSHAFT) ${ }^{10}$ was written in a modular form to allow the addition of new configurations. The current simulation, which is now called TLIFE, adds significantly to the number and complexity of transmissions which can be analyzed. Helical gear transmissions and single and dual input spiral bevel transmissions have been added to the basic transmission set and a method of combining basic transmissions to simulate more complex systems has been devised. This saves the effort and time involved in developing code to simulate a new transmission which may be composed of the same unit transmissions in a different order. Also, the modular construction of the program simplifies adding a new unit configuration to the program.

This paper describes the computer program TLIFE for life and reliability analysis of aircraft transmissions and illustrates its use. The program has been written in ANSI standard FORTRAN 77 and runs both on the personal computer in the DOS environment and on the mainframe computer in the UNIX environment.

The life and reliability analysis in this simulation is based on the assumption that the transmissions are well lubricated and the gears well designed and of high quality so that failure by tooth breakage and tip scoring are avoided and surface pitting is the only mode of failure. 25.6

The input file includes the transmission configuration, specification of input torque and input speed for the first transmission and the locations, types, and basic dynamic capacities of the gears and bearings for all unit transmissions of which the overall transmission is composed from input to output. The basic dynamic capacities are the forces that the components can carry for one-million load cycles with a 90-percent probability of survival.

For each unit transmission analyzed, the output file includes an echo of the input data; a listing of the component loads, basic dynamic capacities, life factors, geometries, and adjusted dynamic capacities; followed by a listing of each component's and the unit transmission's output dynamic capacity, load-life, and Weibull exponents and 90-percent and mean lives. Here the adjusted capacities are the basic dynamic capacities of the components in units of force including the life and load adjustment factors, and the output dynamic capacities are the output torques required to cause loads of these magnitudes on the components.
Examples of a spiral bevel gear design and a compound helical gear design are presented to illustrate the flexibility of the program. The compound helical gear example can be analyzed directly as a compound transmission or as two single mesh reductions in series. Following the examples, short descriptions of the program structure and analyses methods are given.

\section{Program Capability}

The program can analyze eleven basic transmission configurations, which are composed of spur, helical, and spiral bevel gears. These unit reductions, listed in the order of program analysis, are:

(1) the single mesh spur gear reduction,

(2) the single mesh helical gear reduction,

(3) the compound spur gear reduction,

(4) the compound helical gear reduction,

(5) the parallel compound spur gear reduction,

(6) the parallel compound helical gear reduction,

(7) the reverted spur gear planetary or star reduction,

(8) the reverted helical gear planetary or star reduction,

(9) the single plane spur gear planetary or star reduction,

(10) the spiral bevel reduction and

(11) the dual spiral bevel reduction.

Figure 1 is a schematic of the single mesh reductions in this list, which are items $1,2,10$, and 11 . In the figure, items 1 and 2 are shown with both an external final gear and an internal final gear. The dual spiral bevel reduction is a single reduction with two input gears and a single combining output gear. Figure 2 is a schematic of the compound mesh reductions in the list, which are items 3 to 6 ; and Fig. 3 is a schematic of the planetary and star unit reductions which comprise items 7 to 9 in the list.

Each single mesh reduction has single gears mounted on its input and output shafts which are supported by two bearings each. These gears can be supported either in straddle or in overhung configurations, as shown in Fig. 4. The locations of the bearings are specified by the distances A and B which are measured from the gear center to the bearing center. The bearings can be single or double row ball or cylindrical roller bearings or double row tapered roller bearings. For the helical and spiral bevel gear cases, at least one of the bearings on each shaft must be either a ball bearing or a tapered roller bearing to support the axial load. The analysis assumes that one bearing takes the thrust load, or that both bearings share the thrust load equally, as specified by the user. The dual spiral bevel reduction has three spiral bevel gears and six bearings. The two input pinions are assumed to be identical in all respects. 
The compound mesh reductions, shown in Fig. 2, have input and output shafts which are similar to those of the single mesh reductions. They also have one or two intermediate shafts which support two intermediate gears on two bearings. The input and intermediate gears are external gears and the output gear may be an external gear, or an internal ring gear. The intermediate gears may be supported in any of the four ways shown schematically in Fig. 5, which are:

(1) double straddle,

(2) double overhung,

(3) output gear overhung, and

(4) input gear overhung.

Distances $\mathrm{C}$ and $\mathrm{E}$ give the distances of the two bearings from the gears and distance $\mathrm{D}$ gives the distance between the two gears, with all measurements from center to center. For the parallel compound spur and helical reductions, it is assumed that the two intermediate shafts are identical in all respects. The output shaft may be on the same side of the intermediate shafis as the input shaft as shown in Fig. 2 or may be on the opposite side.

The planetary and star reductions, which are shown schematically in Fig. 3, include the reverted reductions and the single plane reduction which can only be a spur reduction since the program's analysis assumes there are no axial loads on the single plane planet bearings. The reverted reductions have an input gear, a final gear, which may be external or internal, and at least two identical intermediate shaft assemblies with two gears and two bearings symmetrically spaced about the collinear input and output gears. The intermediate shaft sub-assemblies may have any of the four configurations shown in Fig. 5. The output of the reduction unit may be either the final gear, with the arm holding the intermediate shaft subassemblies fixed, or the arm with the final gear fixed. Taking the output from the arm makes this configuration work as a reverted planetary reduction.

The single plane reduction has an input sun gear and a final ring gear in mesh with a number of planets which are symmetrically placed about the sun and ring gears. This makes the input and output shafts collinear. The planet gears may be unstepped or stepped, with one size of gears meshing with the sun gear and another size of concentric gears meshing with the ring gear. In order to keep the loads on the planet bearings radial for a transmission with stepped planets, one set of planet gears must be split and straddle the other. The radial loads coming on the planet gears are carried by single, in-plane bearings, fixed relative to the inner race. The output of the reduction unit may be either the final gear, with the arm holding the planets fixed, or the arm with the ring gear fixed for a planetary reduction.

In addition to single unit reductions, up to 25 reduction units may be combined in series for analysis or a two- branch reduction may be analyzed with the dual spiral bevel unit acting as a combining element with a 25-unit limit for one branch. The dual spiral bevel need not be the first unit in the reduction, but its dual inputs are assumed to be equal, so the two branches that feed it must be identical.

\section{Program Use}

The program can be run on any DOS-based PC by using the file "TLIFE.EXE." Since it is written in strict ANSI FORTRAN 77, it can also be run on a UNIX workstation with an executable file compiled in that environment.

Due to the large amount of input data required to define a reduction, the transmission to be analyzed is described in an input data file before running the program. The input file must include the number of unit transmissions, the units of measure and specification of input torque, speed, and direction on the first line. A detailed description of the input file and use of the program TLIFE is available. "The data must be entered into an ASCII file, structured by line, but with a free format on each line. If multiple transmission units are to be analyzed as a system, then the units should be entered in order, with the highest speed unit first and the lowest speed unit last. If a dual spiral bevel unit is included, only one input branch need be entered, as both input branches should be identical.

In series transmissions in which a unit transmission's output shaft and the following unit transmission's input shaft share bearings, the user must specify two bearings for the output shaft of the driving unit and two bearings for the input shaft of the driven unit. Physically, this is the same shaft which only has two bearings. In the analysis, the bearings on the output shaft of the driving unit are used only to determine loads. These loads are superimposed on the bearings of the input shaft of the driven unit along with the input shaft's own loads. The life and reliability of the input shaft bearings are then calculated for the total loads and used in the system life analysis.

For each unit transmission, the output file gives a description of the transmission configuration, transmission characteristics, and the input data for the gears and bearings followed by a report of the loads and basic dynamic capacities. Following this is a summary of the output dynamic capacities in units of output torque, the 90-percent reliability lives in million output rotations and hours and the mean lives in hours for the different components and the unit transmission. The output dynamic capacity and life summary is given for the overall transmission with the overall mean live given as a transmission life and an overall component life. The transmission life predicts the mean life between service overhauls with full transmission replacement, while the overall component mean life predicts the mean time between service overhauls for maintenance by failed component replacement only. 
For transmissions composed of a series of unit transmissions, the overall reduction input and output speeds, torques, and rotational directions are given along with the overall speed reduction and the transmitted power before the unit transmission analyses are given and the dynamic capacity and lives of the overall reduction are written to the end of the output file.

\section{Program Structure}

The structure of the computer program that performs these analyses is shown in the block diagram of Fig. 6. A main program opens the input and output ASCII files, calls a configuration analysis routine, and closes the files after the analysis is completed. In the program, a common block array, PROP, serves as a property database. This array holds the component and transmission property values from the analysis subroutines. It is two-dimensional, with columns corresponding to specific components of a transmission and rows containing values for specific properties. The first column of the array contains the system properties for the entire transmission, and the first column for each unit transmission contains the system properties for that unit.

The main program calls one of three configuration analysis routines to analyze each unit transmission. The configuration routines match the configuration groupings of Figs. 1 to 3. SMESH analyzes the single mesh unit transmissions, COMRED analyzes the compound transmissions and PLANET analyzes the planetary and star configurations.

As indicated in Fig. 6, the program is modular in that the configuration-specific subroutines use the same input and output routines, component analysis routines, basic mathematics subroutines, and system analysis subroutines. For each unit transmission, one of the analysis routines reads in the input data, calculates the component properties and performs component life and capacity analyses. The main program then calls the system life and capacity routines to perform the system analysis and uses the output routines to write the output file.

Since the subroutines that determine the transmission life and dynamic capacity interface directly with the property array, they are separated from any specific transmission configuration. The system analysis subroutines, LIFE and DYN, work in an identical manner for all unit transmission configurations. For the full system, the same routines are used with a pointer array to include all the components in the overall transmission while skipping the unit transmission properties. Thus, other configurations can be added to the program by adding appropriate configuration analysis subroutines.

\section{Analysis Methods}

For each configuration, the analysis begins with a static and kinematic analysis of the reduction to determine the gear and bearing loads and load cycles. Dynamic capacities are then determined for the gears and bearings in the unit transmission. These capacities are used with the LundbergPalmgren life model to determine the service life of the transmission from the component loads and load cycles.

The life model comes from rolling element bearings. ${ }^{12}$ Lundberg and Palmgren determined that the scatter in the life of a bearing can be modeled with a two-parameter Weibull distribution in terms of a 90-percent probability of survival life:

$$
\operatorname{Ln}\left(\frac{1}{R}\right)=\operatorname{Ln}\left(\frac{1}{0.9}\right) \cdot\left(\frac{1}{\digamma_{10}}\right)^{b}
$$

This life to reliability relationship is at a specific load, $F$, which corresponds to the $\ell_{10}$ life. This load, $F$, is related to the component basic dynamic capacity, $C$, as:

$$
\ell_{10}=\left(\frac{C}{F}\right)^{p}
$$

Since the life at the dynamic capacity is one-million load cycles, it does not appear as a variable in the equation.

These equations, which are based on experiment, give the life of the component for a given load, $F$, and reliability level, $\boldsymbol{R}$. By knowing the Weibull slope, $b$, the load-life exponent, $p$, and the dynamic capacity of the component, $C$, one can use these equations to calculate the life of the component for any desired reliability.

The STLE Life Factors Committee modified Eq. (2) with life and load adjustment factors. ${ }^{12}$ These factors extend Eq. 2 to cover many different end use situations so that designers can size bearings properly. The revised equation for $\ell_{10, a}$, which is used in this analysis, is:

$$
I_{10 a}=a\left(\frac{C}{v F_{r}}\right)^{p}
$$

In Eq. (1), the Weibull slope, $b$, is normally $10 / 9$ for ball and $9 / 8$ for straight roller bearings, and in Eqs. (2) and (3), the load-life exponent, $p$, is 3.0 for ball bearings, and 3.33 for roller bearings. 
Since gear tooth pitting failures are similar to bearing failures, with the possible difference of surface initiation, the two-parameter Weibull distribution can be used to describe the scatter in gear life with a different Weibull slope. The load-life relationship of Eq. (2) is given graphically in the ANSI/AGMA standards as a life factor for gears. ${ }^{13}$

To combine these component life models into a model for the service frequency of a transmission, the drive system reliability, $\boldsymbol{R}_{\boldsymbol{r}}$, is treated as a strict series probability of all the component reliabilities. ${ }^{2}$ This makes the system reliability the product of the reliabilities of all the components. The system life can also be expressed as a two-parameter Weibull distribution in terms of the system reliability parameters, $b_{s}$ and $\ell_{10}$ :

$$
\operatorname{Ln}\left(\frac{1}{R_{s}}\right)=\operatorname{Ln}\left(\frac{1}{0.9}\right) \cdot\left(\frac{I_{s}}{l_{10 s}}\right)^{b_{s}}
$$

The system Weibull slope, $b_{s}$, and system 90 -percent reliability, $\ell_{10,}$, can be found by iteration. The system dynamic capacity and load-life factor are found by a similar iteration.

This nominal, high-reliability life can be converted to an estimated service life by calculating the average time to failure for a large number of units in service. The mean time between overhauls for full transmission replacement is this system mean life, which is related to the 90-percent reliability life by the gamma function:

$$
I_{a v}=\frac{I_{10} \cdot \Gamma\left(1+\frac{1}{b}\right)}{\left[\operatorname{Ln}\left(\frac{1}{0.9}\right)\right]^{1 b}}
$$

If the transmission repairs are component repairs rather than full replacement, then a second mean life is required to estimate the mean time between overhauls. This second mean life is the average mean life of the individual components. It is based on a different statistical model in which each component's failure rate is constant and independent. In this model, the transmission failure rate is the sum of the component failure rates. Using the reciprocal of the failure rate as an estimate for the mean life gives:

$$
l_{a v s}=\frac{1}{\sum_{i=1}^{n}\left(\frac{1}{l_{a v 1}}\right)}
$$

This second mean transmission life is labeled the mean component life in the output.
Applications

Two examples are presented to illustrate the program. Figure 7 is a schematic of the first example, a spiral bevel reduction which transmits $105 \mathrm{~kW}$ of power at an input speed of $4000 \mathrm{rpm}$ and torque of $250 \mathrm{~N}-\mathrm{m}$ to an output speed of $2000 \mathrm{rpm}$ and torque of $500 \mathrm{~N}-\mathrm{m}$. The gears have 21 and 42 teeth, a back-cone distance of $120 \mathrm{~mm}$ and a face width of $30 \mathrm{~mm}$ with a shaft angle of $110^{\circ}$. The bearings have $55 \mathrm{~mm}$ bores and are located 75 and $200 \mathrm{~mm}$ behind their respective gear centers. The bearings are 300 series with the close bearings being roller and the far bearings being ball and supporting the thrust loads.

Table 1 lists the equivalent radial loads, adjusted basic dynamic capacities, and mean lives of the four bearings and two gears and the life of the unit transmission as found by the program. The loads and capacities are in force units since they are both directly on the components. The adjusted capacity is the load which would produce a one-million load-cycle life with a 90-percent reliability for that component, including life and load adjustment factors. In this example one can see the strong influence of the bearing capacities on the transmission service life. One can also see that the service life is greater at $1145 \mathrm{hr}$ for replacing the entire transmission than $1020 \mathrm{hr}$ for replacing only the failed component in a maintenance session. By replacing the entire transmission, one replaces components with partial damage in addition to the failed component-thus extending the service life of the repaired transmission at a larger material cost per maintenance. These two lives are close to each other, due to the short life of the input shaft ball bearing relative to the lives of the other components in the transmission.

Figure 8 shows the second example, a two stage helical reduction which takes an input torque of $100 \mathrm{~N}-\mathrm{m}$ at 5000 rpm and reduces it to an output torque of $900 \mathrm{~N}-\mathrm{m}$ at $556 \mathrm{rpm}$ at a power level of $52 \mathrm{~kW}$. The transmission has four gears and six bearings and was modeled both as a compound helical reduction and as two single mesh helical reductions in series. Both analyses yielded the same results. The two gear reductions are each 3:1 with the first one having a 13 tooth pinion and a 39 tooth gear and the second one having a 14 tooth pinion and a 42 tooth gear. The input gear mesh has: a normal module of $4.5 \mathrm{~mm}$, a helix angle of $30^{\circ}$, and a face width of $20 \mathrm{~mm}$. The output gear mesh has: a module of $6 \mathrm{~mm}$, a helix angle of $25^{\circ}$, and a face width of $35 \mathrm{~mm}$. All bearings are 300 series, with the input bearings having a $55 \mathrm{~mm}$ bore and the other four bearings having a $75 \mathrm{~mm}$ bore. Each shaft has one ball bearing and one roller bearing, with the ball bearing carrying the lighter radial load and the thrust load. The near bearings are $50 \mathrm{~mm}$ from their respective gears and the far bearings are $150 \mathrm{~mm}$ from the gears as shown in Fig. 8 . 
Table 2 lists the equivalent radial loads, adjusted dynamic capacities, and mean lives of the six bearings and four gears and the lives of the unit transmissions as found by the program. Once again, the bearings are the critical elements in determining the life of the transmission. The input shaft sees the highest load cycle count at the highest speed, but has the lowest loads and the smallest bearings. In contrast, the output shaft has the lowest speed and high loads with larger bearings. The intermediate shaft has the same size bearings as the output shaft but has higher loads and a higher speed than the output shaft. This combination of loading, speed factor derating and high cycle-count make these bearings significant in the life analysis. As in the first example, the transmission service life is shorter than that of the weakest component but is close to it indicating that the design is somewhat out of balance and is service limited by a single component. With the larger number of components, there is a greater disparity between the full transmission replacement service life of $3145 \mathrm{hr}$ and the failed component replacement service life of $2660 \mathrm{hr}$. Analyses such as the one available through this program can assist the designer in obtaining more optimal designs at an early stage.

\section{$\underline{\text { Conclusions }}$}

A generalized life and reliability model has been applied to predict the service life of aircraft transmissions composed of spur, helical, and spiral bevel gears with ball, straight roller, and tapered roller bearings. Models such as this are needed to enable the evaluation of transmission service life before the transmission is constructed. With this model, one can optimize the transmission to maximize the system service life while maintaining given power and weight constraints.

The model has been applied to single mesh transmissions as well as compound and planetary transmissions and transmissions composed of unit transmissions in series. The life model for this analysis is the two-parameter Weibull failure distribution, which has been applied to the bearings and gears of the transmissions as well as the overall transmission systems.

The FORTRAN program, TLIFE, which performs these analyses has been described and its use illustrated with two design examples. A spiral bevel single mesh transmission was analyzed for its service life at a given power level as specified by its input torque and speed. A compound helical gear transmission was analyzed first as a single compound reduction and again as two single mesh reductions in series to illustrate the flexibility of the program. This transmission was analyzed for its service life at a specified power level. The separate service lives of the two component parts of this transmission were presented as well. Both analyses of the compound helical gear transmission produced the same results.
Component analyses indicate the service life limiting factors in the transmissions so they can be overcome to improve the overall life of the transmission before the transmission is constructed.

\section{$\underline{\text { References }}$}

1. Ludemann, S.G., "Prop-Fan Powered Aircraft-An Overview," SAE Paper 820957, Aug. 1982.

2. Savage, M. and Lewicki, D.G., "Transmission Overhaul and Replacement Predictions Using Weibull and Renewal Theory," AIAA Joumal of Aircraft Propulsion and Power, Vol. 7, No. 6, Nov.-Dec. 1991, pp. 1049-1054.

3. Dietrich, M., Stajszczak, M., and Szopa, T., "Computer Aided Gear Reliability Evaluation," Proceedings of The International Conference on Motion And Power Transmission, Hiroshima, Japan, Nov. 1991, pp. 502-507.

4. Joachim, F.J., "Application of Modern Calculation Methods to Gears in Vehicle Transmissions," Proceedings of The International Conference on Motion And Power Transmission, Hiroshima, Japan, Nov. 1991, pp. 583-588.

5. Coy, J.J., Townsend, D.P., and Zaretsky, E.V., "Dynamic Capacity and Surface Fatigue Life for Spur and Helical Gears," ASME Joumal of Lubrication Technology, Vol. 98, No. 2, Apr. 1976, pp. 267-276.

6. Lewicki, D.G., Black, J.D., Savage, M., and Coy, J.J., "Fatigue Life Analysis of A Turbo-Prop Reduction Gearbox," ASME Journal of Mechanisms, Transmissions, and Automation in Design, Vol. 108, No. 3, June 1986, pp. 255-262.

7. Savage, M., Paridon, C.A., and Coy, J.J., "Reliability Model for Planetary Gear Trains," ASME Journal of Mechanisms, Transmissions, and Automation in Design, Vol. 105, No. 3, Sept. 1983, pp. 291-297.

8. Savage, M., Brikmanis, C.K., Lewicki, D.G., and Coy, J.J., "Life and Reliability Modeling of Bevel Gear Reductions," ASME Joumal of Mechanisms, Transmissions and Automation in Design, Vol. 110, No. 2, June 1988, pp. 189-196.

9. Savage, M., Radil, K.C., Lewicki, D.G., Coy, J.J., "Computerized Life And Reliability Modeling for Turbo-Prop Transmissions," NASA TM 100918, 1988, AlAA Journal of Propulsion and Power, Vol. 5, No. 5, Sept.-Oct. 1989, pp. 610-614. 
10. Savage, M., "Life and Dynamic Capacity Modelling for Aircraft Transmissions," NASA CR-4341, Jan. 1991.

11. Savage, M., Prasanna, M.G., and Rubadeux, K.L., "TLIFE-A Program for Spur, Helical and Spiral Bevel Transmission Life And Reliability Modeling," NASA CR (in press), 1994.
12. Zaretsky, E.V., STLE Life Factors for Rolling Bearings. Society of Tribology and Lubrication Engineers, Park Ridge, IL, 1992.

13. AGMA STANDARD, "Fundamental Rating Factors and Calculation Methods for Involute Spur and Helical Gear Teeth," ANSUAGMA 2001-B88, Alexandria, VA, Sept. 1988.

TABLE 1.-SPIRAL BEVEL REDUCTION LOADS AND LIVES

\begin{tabular}{|l|c|c|r|}
\hline & $\begin{array}{c}\text { Load, } \\
\mathrm{kN}\end{array}$ & $\begin{array}{c}\text { Adjusted capacity, } \\
\mathrm{kN}\end{array}$ & \multicolumn{1}{|c|}{$\begin{array}{c}\text { Mean life, } \\
\mathrm{H}\end{array}$} \\
\hline Pinion & 6.3 & 34.1 & 8240000 \\
Pinion roller bearing & 7.8 & 52.3 & 3430 \\
Pinion ball bearing & 4.8 & 31.9 & 1940 \\
Gear & 6.3 & 35.7 & 12490000 \\
Gear roller bearing & 9.0 & 76.2 & 7750 \\
Gear ball bearing & 3.0 & 47.5 & 25655 \\
Transmission & & & 1145 \\
Components & & & 1020 \\
\hline
\end{tabular}

TABLE 2.-TWO-STAGE HELICAL REDUCTION LOADS AND LIVES

\begin{tabular}{|l|r|c|r|}
\hline & $\begin{array}{c}\text { Load, } \\
\mathrm{kN}\end{array}$ & $\begin{array}{r}\text { Adjusted capacity, } \\
\mathrm{kN}\end{array}$ & $\begin{array}{c}\text { Mean life. } \\
\mathrm{H}\end{array}$ \\
\hline Input pinion & 3.6 & 14.6 & 533675 \\
Input roller bearing & 4.6 & 44.9 & 11845 \\
Input ball bearing & 2.1 & 27.1 & 14650 \\
First gear & 3.6 & 15.7 & 1031690 \\
Intermediate roller bearing & 12.8 & 135.6 & 15820 \\
Intermediate ball bearing & 7.0 & 72.4 & 7370 \\
Second pinion & 7.6 & 33.7 & 1351390 \\
Output gear & 7.6 & 36.3 & 2612485 \\
Output roller bearing & 12.6 & 259.1 & 139640 \\
Output ball bearing & 6.4 & 142.9 & 75530 \\
First stage & & & 7040 \\
Second stage & & & 5015 \\
Transmission & & & 3145 \\
Components & & & 2660 \\
\hline
\end{tabular}



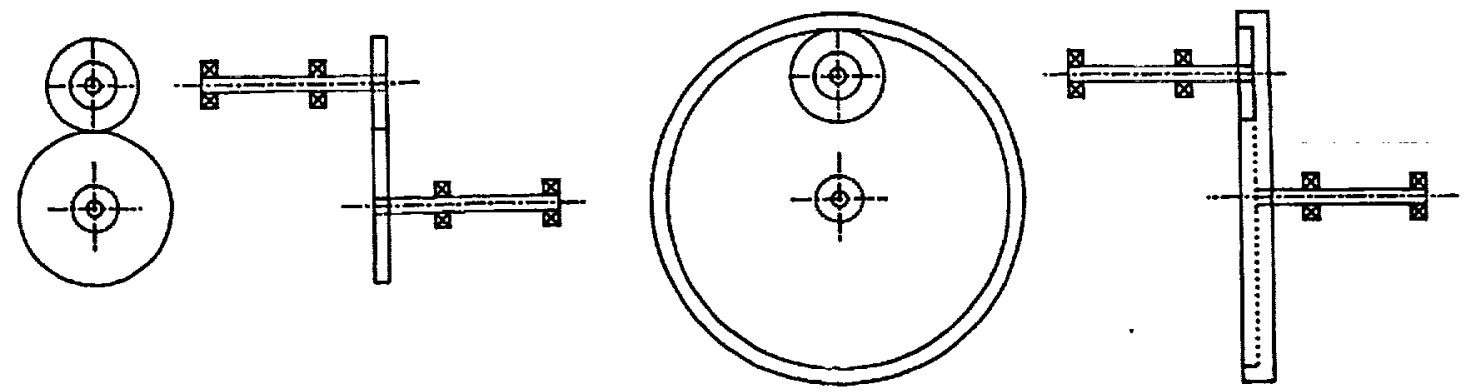

EXTERNAL SPUR AND HELICAL

INTERNAL SPUR AND HELICAL
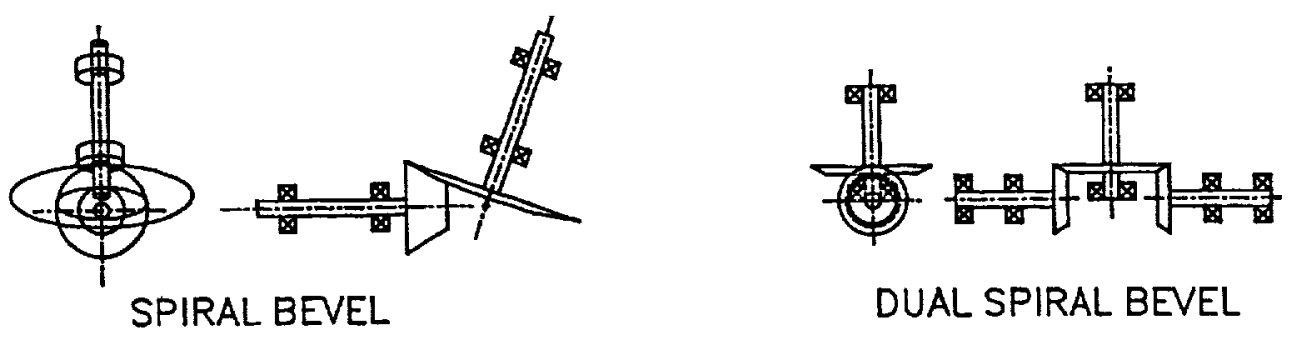

FIGURE 1 - SINGLE MESH UNIT TRANSMISSIONS
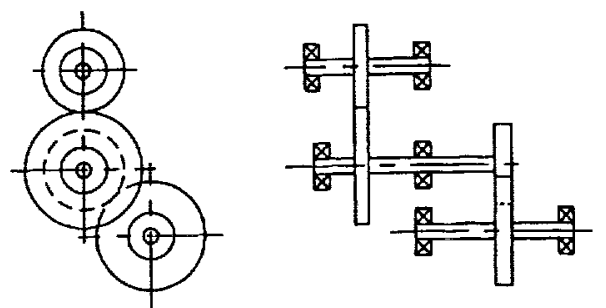

COMPOUND SPUR AND HELICAL

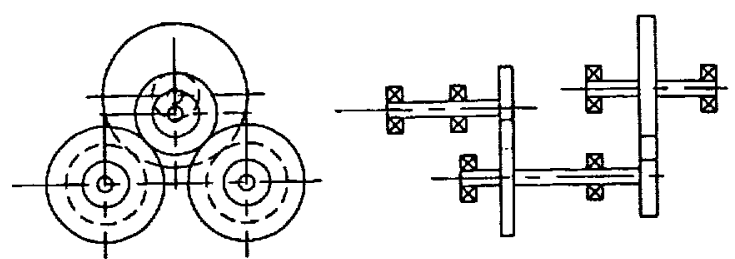

PARALLEL COMPOUND SPUR AND HELICAL

FIGURE 2 - COMPOUND MESH UNIT TRANSMISSIONS 


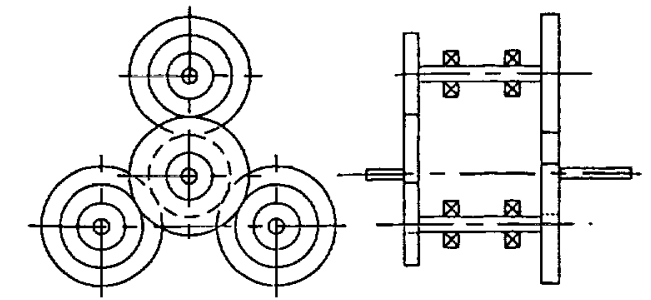

REVERTED SPUR AND HELICAL
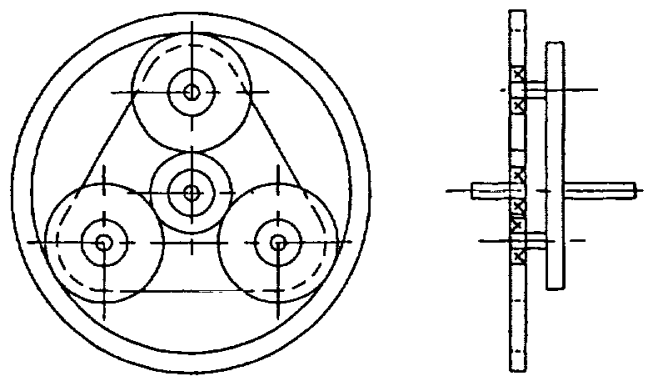

SINGLE PLANE SPUR

FIGURE 3 - PLANETARY AND STAR UNIT TRANSMISSIONS

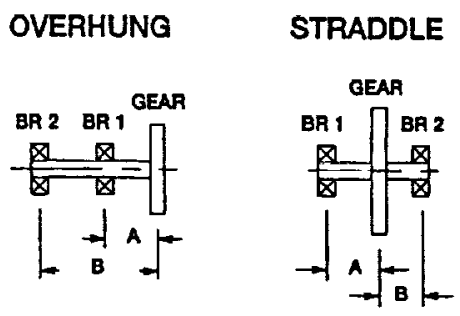

SPUR AND HELICAL

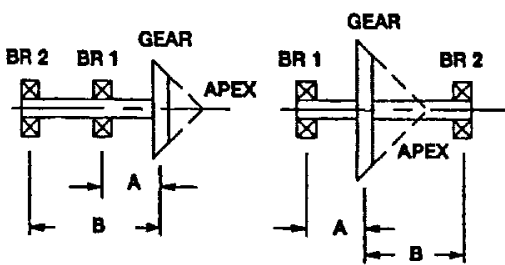

SPIRAL BEVEL

FIGURE 4 - INPUT AND OUTPUT SHAFT BEARING CONFIGURATIONS

DOUBLE STRADDLE

DOUBLE OVERHUNG

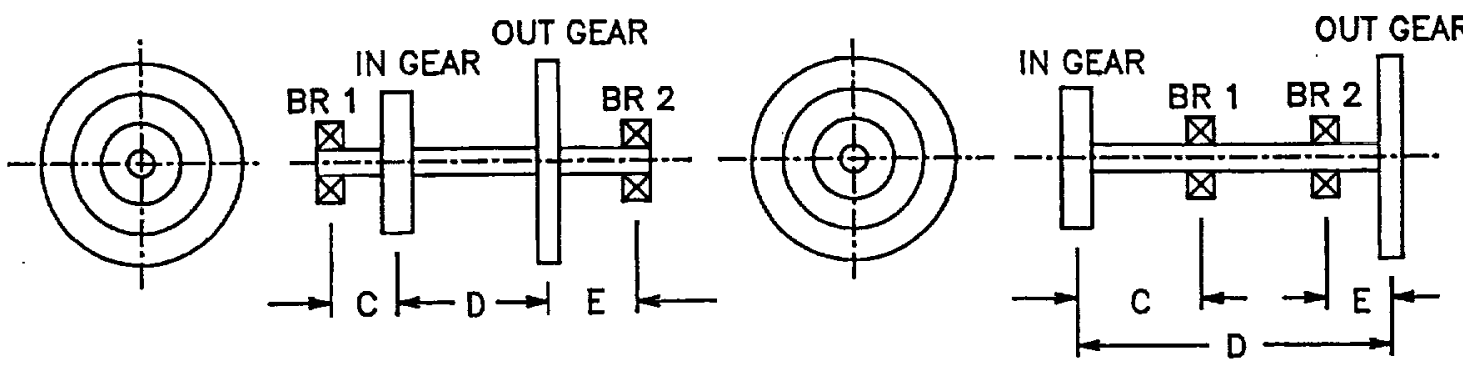

OUTPUT GEAR OVERHUNG

INPUT GEAR OVERHUNG
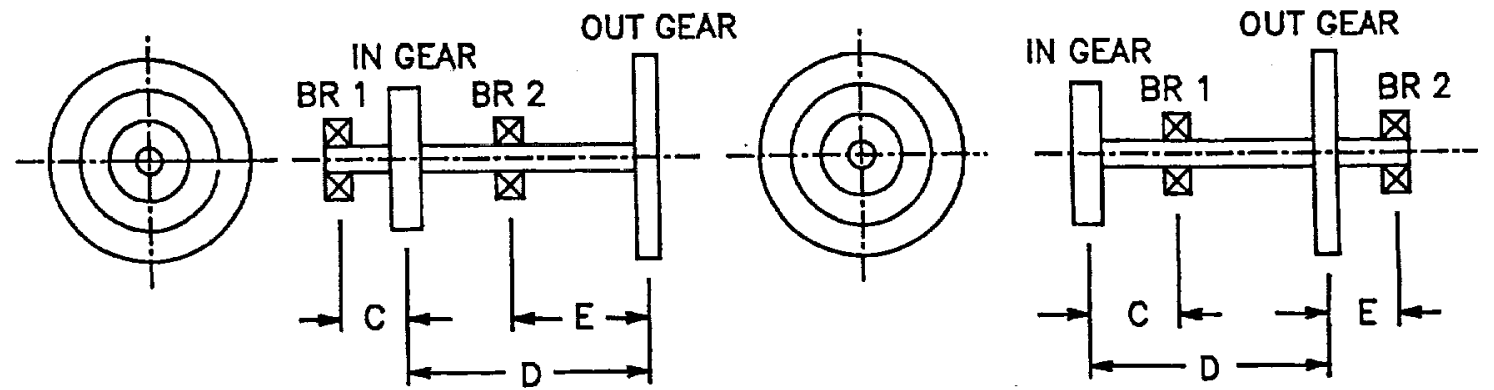

FIGURE 5 - INTERMEDIATE SHAFT BEARING CONFIGURATIONS 


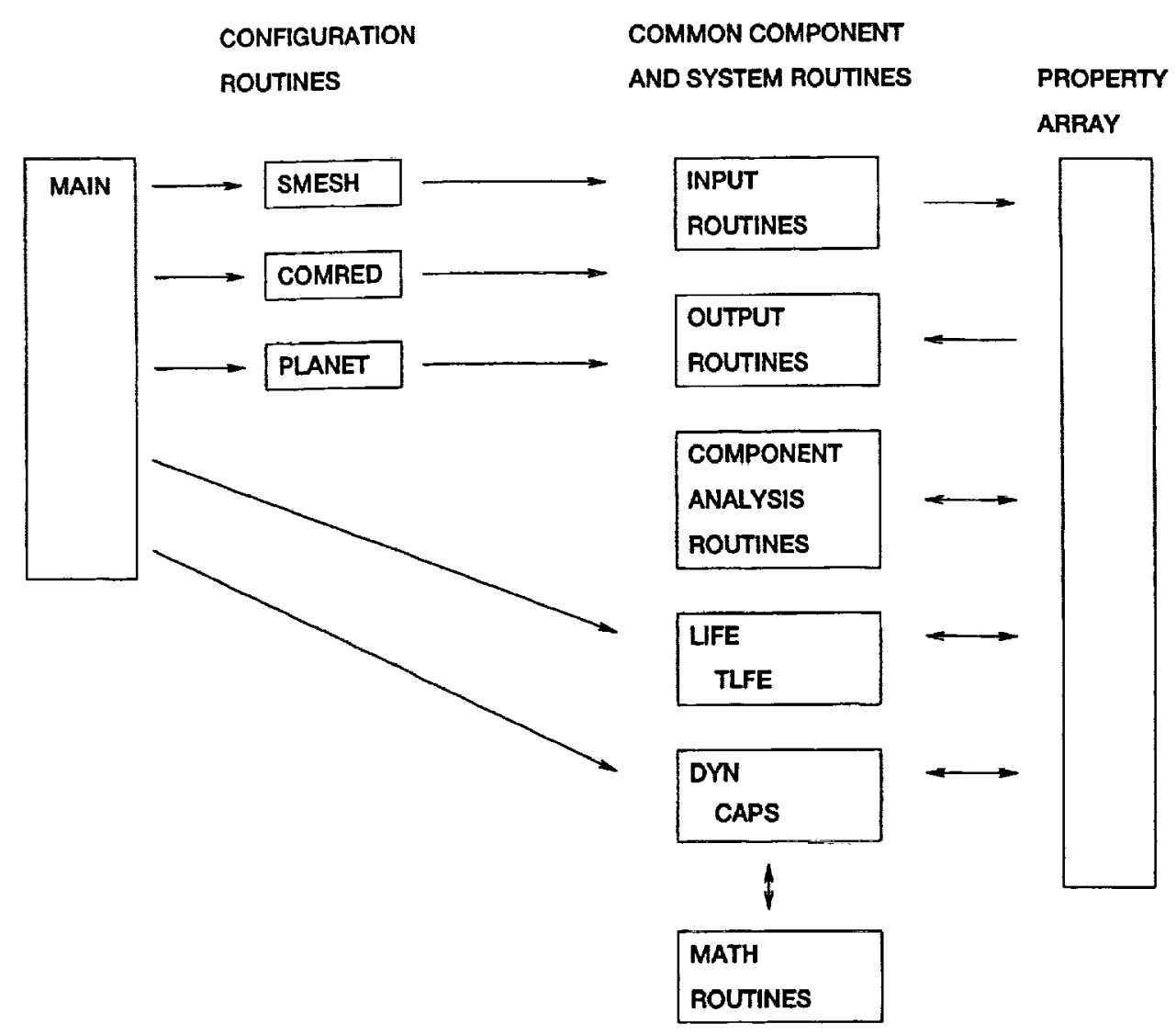

FIGURE 6 - TLIFE PROGRAM BLOCK DIAGRAM
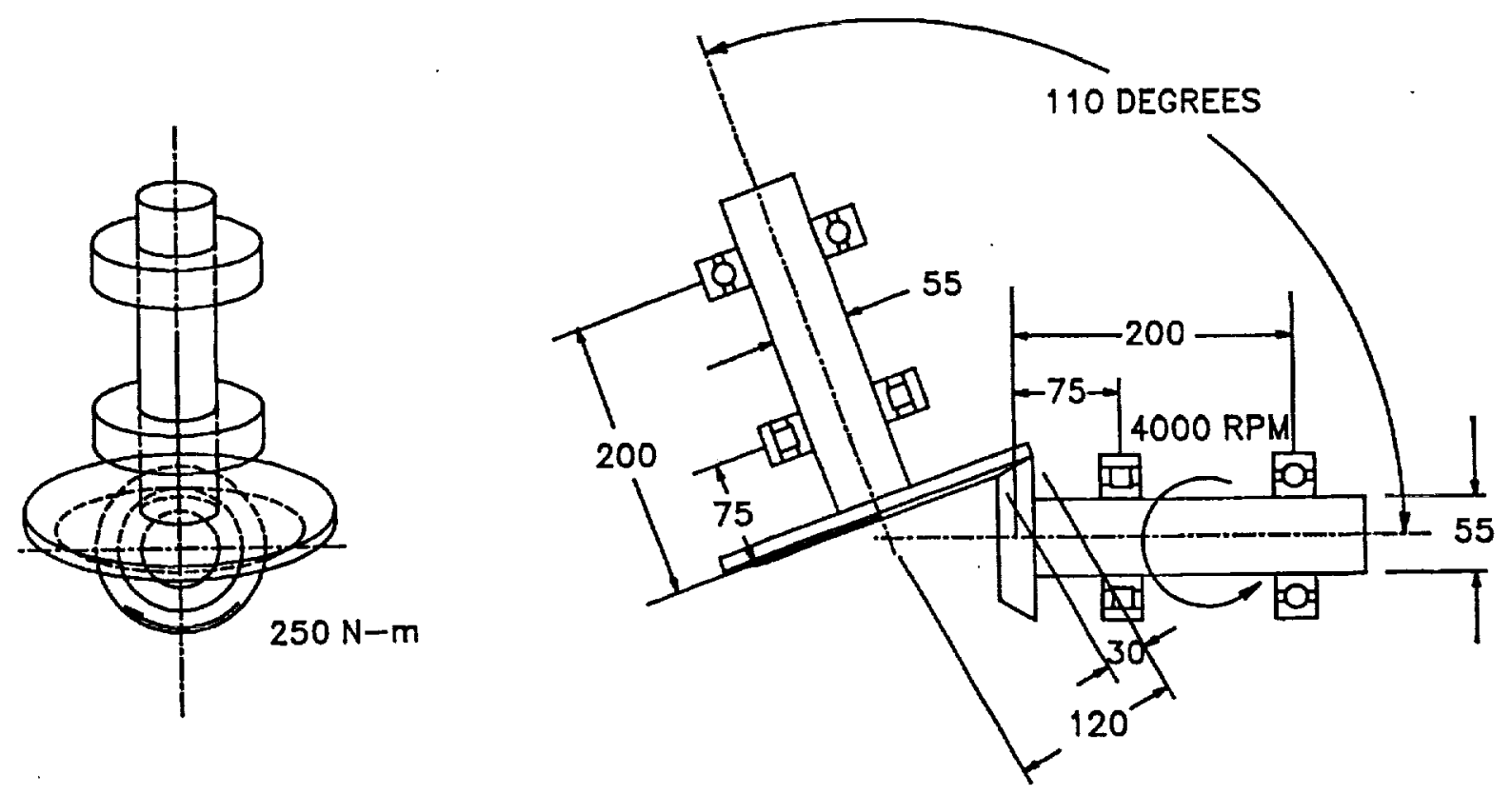

FIGURE 7 - SPIRAL BEVEL REDUCTION 


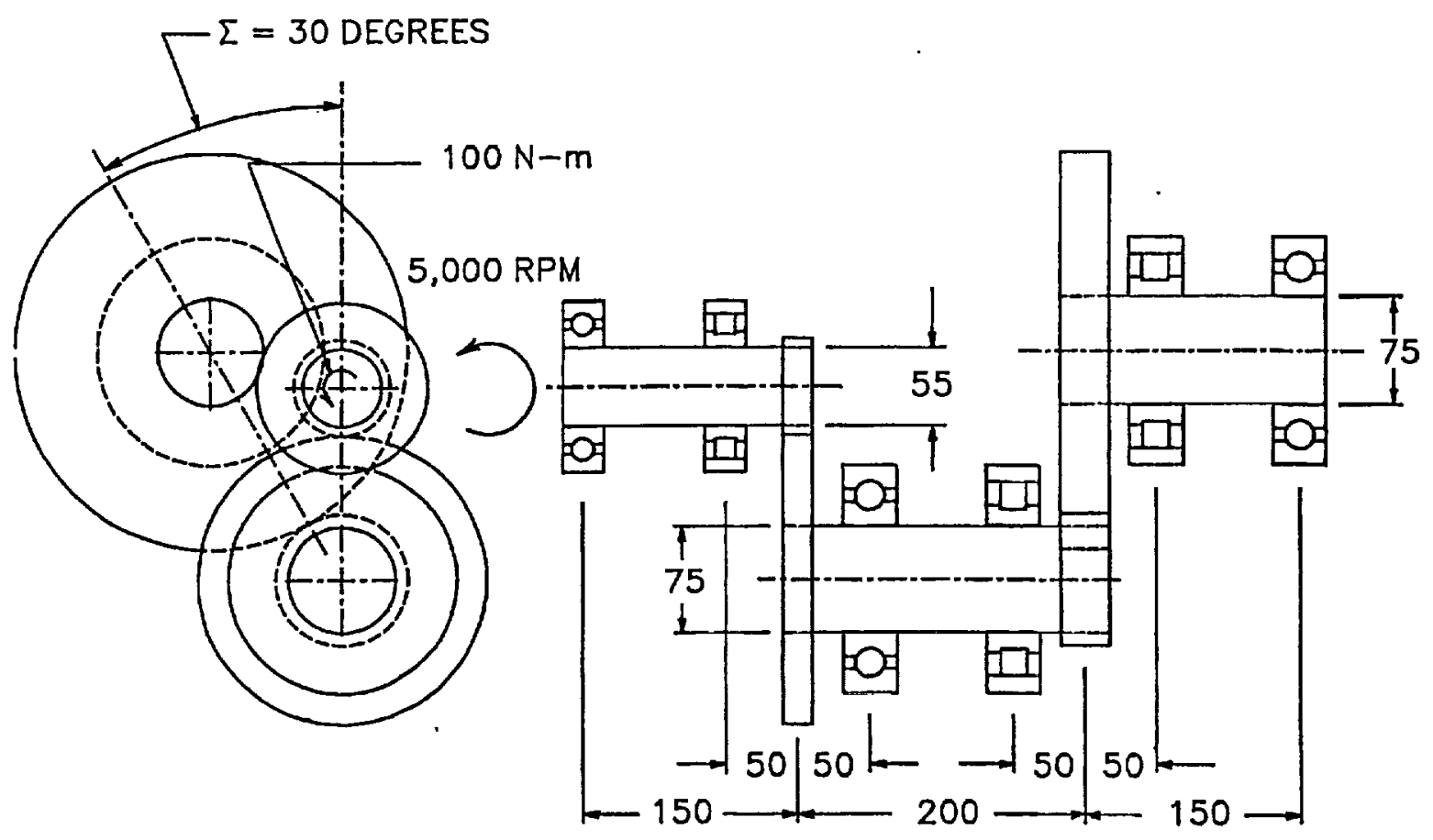

FIGURE 8 - TWO STAGE HELICAL REDUCTION 


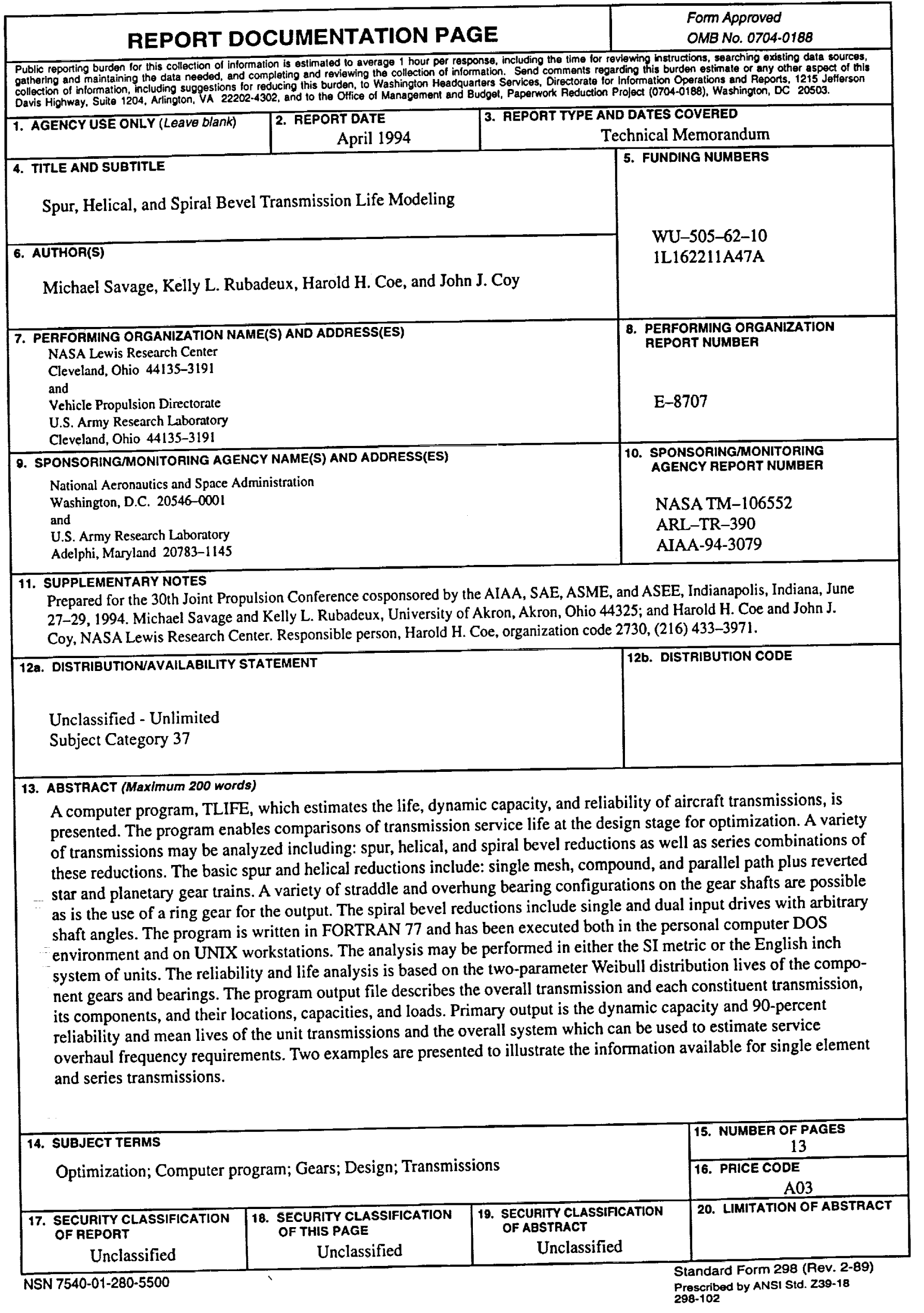

